\title{
Biomaterials
}

\section{A new approach based on injection moulding to produce biodegradable starch-based polymeric scaffolds: morphology, mechanical and degradation behaviour}

\author{
M.E. Gomes*, A.S. Ribeiro, P.B. Malafaya, R.L. Reis, A.M. Cunha \\ Department of Polymer Engineering, University of Minho, Campus de Gualtar, 4710-057 Braga, Portugal \\ Received 1 February 2000; accepted 15 July 2000
}

\begin{abstract}
One of the present challenges in polymer scaffold processing is the fabrication of three-dimensional (3D) architectures with an adequate mechanical performance to be used in the tissue engineering of hard tissues. This paper describes a preliminary study on the development of a new method to produce biodegradable scaffolds from a range of corn-starch-based polymers. In some cases, hydroxlapatite was also used as a reinforcement of the biodegradable polymers. The developed methodology consists of a standard conventional injection moulding process, on which a solid blowing agent based on carboxylic acids is used to generate the foaming of the bulk of the moulded part. The proposed route allows for the production of scaffolds with a compact skin and a porous core, with promising mechanical properties. By using the developed method it is possible to manufacture biodegradable polymer scaffolds in an easy (melt-based processing) and reproducible manner. The scaffolds can be moulded into complex shapes, and the blowing additives do not affect the non-cytotoxic behaviour of the starch-based materials. The materials produced using this method were evaluated with respect to the morphology of the porous structure, and the respective mechanical properties and degradation behaviour. It was demonstrated that it is possible to obtain, by a standard melt based processing route, 3D scaffolds with complex shapes that exhibit an appropriate morphology, without decreasing significantly the mechanical properties of the materials. It is believed that the optimisation of the proposed processing methodology may lead to the production of scaffolds that might be used on the regeneration of load-bearing tissues. (C) 2001 Elsevier Science Ltd. All rights reserved.
\end{abstract}

Keywords: Biodegradable polymers; Hard-tissue engineering; Starch-based biomaterials; Scaffold processing

\section{Introduction}

The advent of tissue engineering has been motivated by the challenge of producing tissue substitutes that can restore the structural features and physiological functions of natural tissues in vivo [1,2]. It is a hybrid technology that combines biology and materials science. In most cases, biocompatible, degradable polymers are utilised to induce surrounding tissue ingrowth or to serve as temporary scaffolds for transplanted cells to attach, grow and maintain differentiated functions [2-8].

However, the requirements for such type of materials are complex and not totally understood by the biomaterials research community. In addition to being

\footnotetext{
* Corresponding author. Tel.: 351-253-604498; fax: 351-253-604492.

E-mail address: megomes@dep.uminho.pt (M.E. Gomes).
}

biocompatible both in as-implanted and degraded form, these scaffolds have to exhibit appropriate mechanical properties to provide the correct stress environment for the neo-tissue [1,6,9-12]. The material must be designed with a degradation rate that assures that the strength of the scaffold is retained until the newly grown tissue takes over the synthetic support $[2,3,6,10,11,13]$. Also, the scaffolds should be porous and permeable to permit the ingress of cells and nutrients and should exhibit the appropriate surface chemistry for cell attachment and proliferation [2,3,6,9-11,13-15].

Polymer processing is another key issue that should be addressed. In fact, methods of manufacturing such scaffolds in a reproducible manner are crucial to their success, and must allow for the necessary scale-up of the developed tissue engineering technology [5,9]. The technique used to manufacture scaffolds for tissue engineering is dependent on the properties of the polymer and its 
intended application [16]. It must allow the preparation of scaffolds with complex 3D geometries with controlled porosity and pore size, since these factors are associated with supplying of nutrients to transplanted and regenerated cells and thus are very important factors in tissue regeneration $[3,16]$.

Various processing techniques have and are being developed to fabricate these scaffolds, such as solvent casting $[4,9,16,17]$, particulate leaching $[3,4,9,16,17]$, membrane lamination $[4,18]$, fiber bonding $[4,16,19]$, phase separation/inversion [4,20], high-pressure-based methods [4,21], melt-based technologies [16,22,23], and micro-wave baking and expansion [24], for example. The major problem of the scaffolds produced by the methods developed so far is their mechanical weakness, which does not allow for their use in hard-tissue regeneration where high-strength scaffolds are required [10]. Therefore, the search for better ways of producing porous scaffolds, so that physical and chemical properties can be simultaneously optimised, is currently an important issue in hard tissue engineering research [25].

This work reports the development of degradable porous architectures made of different polymers based on blends of corn starch with: (i) ethylene vinyl alcohol (SEVA-C) and (ii) with cellulose acetate (SCA). These polymeric blends present a non-cytotoxic behaviour and are under consideration for a wide range of biomedical applications [24,26-32]. The proposed processing technique is based on a conventional injection moulding process, using solid blowing agents mainly composed of carboxylic acids.

\section{Materials and methods}

The polymers used in this study are based on blends of corn starch with: (i) ethylene vinyl alcohol (SEVA-C) and (ii) corn starch with cellulose acetate (SCA), both from Novamont, Italy.

The blowing agent (BA) selected for the study is a master-batch of commercial origin (trade name Hostalon P 9947, from Hoechst, Germany), mainly composed of carboxylic acids which reacts by heating, releasing $\mathrm{CO}_{2}$ and water.

The experimental plan included the preparation of compounds of SEVA-C with $0,5,10$ and $20 \mathrm{wt} \%$ of blowing agent and compounds of SCA with 0,5 and $10 \mathrm{wt} \%$ of blowing agent. The polymers and the blowing agents were pre-mixed together in a bi-axial rotating drum prior to injection moulding. Materials were then moulded in two different machines: a Klockner Ferromatic FM-20 and a Krauss Maffei KM60-120A in order to produce ISO tensile $\left(4 \times 10 \mathrm{~mm}^{2}\right.$ of cross-section $)$ and impact samples $\left(6 \times 12 \mathrm{~mm}^{2}\right.$ of cross-section). All samples were tested as-processed.

Some of the materials were reinforced with hydroxyapatite (HA, Plasma Biotal, UK), with $90 \%$ of the particles below $6.5 \mu \mathrm{m}$. In this case, granules with amounts of 10 and $30 \mathrm{wt} \%$ of HA, previously compounded in a twin screw extruder (TSE), were used for the injection moulding trials.

The materials obtained by the described process were characterised in terms on their morphology and physical properties. An optical polarised light transmission microscope (PLM) Olympus BH-A, and a scanning electron microscope (SEM), JEOL JSM 35C and Leica Cambridge, were used for the morphological characterisation.

For the characterisation of the mechanical properties, the materials were tensile tested in order to determine the secant modulus at $1 \%$ strain $\left(E_{1 \%}\right)$ and the ultimate tensile strength (UTS). These tests were performed on a Instron 4505 universal mechanical testing machine fitted with a resistive extensometer (gauge length, $10 \mathrm{~mm}$ ) in a controlled environment $\left(23^{\circ} \mathrm{C}\right.$ and $\left.55 \% \mathrm{RH}\right)$. The cross-head speed was $5 \mathrm{~mm} / \mathrm{min}\left(8.3 \times 10^{-5} \mathrm{~m} / \mathrm{s}\right)$ until $1 \%$ strain, in order to determine with higher precision the $E_{1 \%}$ value, and then increased to $50 \mathrm{~mm} / \mathrm{min}$ $\left(8.3 \times 10^{-4} \mathrm{~m} / \mathrm{s}\right)$ until fracture. The samples with crosssection of $4 \times 10 \mathrm{~mm}^{2}$ were used for the tensile tests.

For a more complete understanding of the mechanical behaviour under different types of mechanical solicitation, the materials were also tested using a three-pointbending loading scheme. In this case, a specific tool was placed between the compression plates of the Instron 4505 universal testing machine. The tool was intended to allow the use of a universal testing machine (working with compression plates) to perform three-point-bending tests (see scheme in Fig. 1). An anvil span of $40 \mathrm{~mm}$ was used as indicated in the figure. The testing speed was $5 \mathrm{~mm} / \mathrm{min}\left(8.3 \times 10^{-5} \mathrm{~m} / \mathrm{s}\right)$.

The flexural modulus $\left(E_{\mathrm{f}}\right)$ and the flexural strength $\left(\sigma_{\mathrm{f}}\right)$ were computed. Again $4 \times 10 \mathrm{~mm}^{2}$ samples were used for these tests. One batch of samples was previously indented with a V-shape $2 \mathrm{~mm}$ deep notch.

The produced scaffolds were also impact tested in order to study the materials behaviour under a more severe loading condition, to observe the resulting fracture morphology and to determine the respective properties,

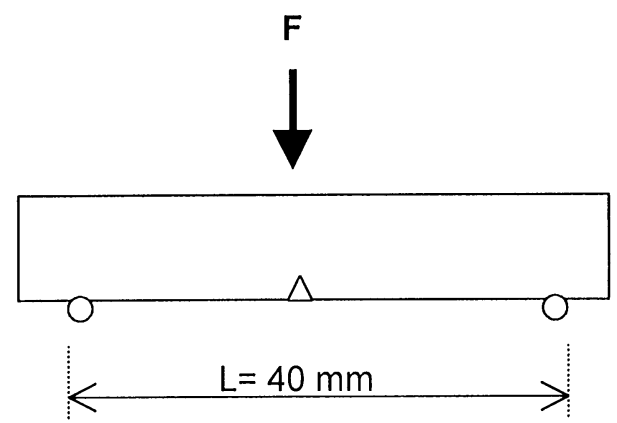

Fig. 1. Schematic representation of the three-point-bending testing method. 
namely, peak force $\left(F_{\mathrm{p}}\right)$, peak energy $\left(U_{\mathrm{p}}\right)$ and impact strength $\left(\sigma_{\mathrm{i}}\right)$. The later parameter has been calculated based on the measured $F_{\mathrm{p}}$ and on a quasi-static threepoint-bending equation. Instrumented impact tests were performed using a mass of $25 \mathrm{~kg}$ and a testing velocity of $3 \mathrm{~m} / \mathrm{s}$, in a Rosand IFW $5 \mathrm{~A}$ instrumented falling-weight equipment. All samples have been previously indented with a V-shape $2 \mathrm{~mm}$ deep notch. The sample dimensions were $60 \mathrm{~mm}(40 \mathrm{~mm}$ of applied span $) \times 12 \mathrm{~mm}(10 \mathrm{~mm}$ un-notched) $\times 6 \mathrm{~mm}$.

The degradation behaviour was assessed after several pre-fixed ageing periods $(0,3,7,14$ and 60 days), in an isotonic saline solution $(\mathrm{NaCl} 0.154 \mathrm{M})$. At the end of each degradation period, the samples were removed from the solution, rinsed with distilled water and weighted, to determine the water uptake; one batch of samples was then dried up to exhaustion $\left(6\right.$ days at $\left.60^{\circ} \mathrm{C}\right)$ in order to determine the dry weight loss; the other batch of samples was dried in a controlled environment of $25^{\circ} \mathrm{C}$ and $55 \%$ $\mathrm{RH}$, to be tensile tested in order to evaluate the changes in the mechanical properties as a function of the degradation time. Degraded samples were also analysed for possible changes in the morphology of the structures by SEM and by energy dispersive spectroscopy (EDS), in a NORAN instrument equipment in order to identify any possible migration of elements from the solution to the bulk of the scaffolds.

\section{Results and discussion}

\subsection{Morphology of the structures}

During the injection moulding process, the blowing agent previously mixed with the polymer reacts by heating, releasing $\mathrm{H}_{2} \mathrm{O}$ and $\mathrm{CO}_{2}$ which is dissolved in the polymer matrix, leading to the formation of macropores in the interior of the resulting samples. These macropores are trapped in the polymer melt and then became surrounded by a compact surface layer. Therefore, the materials obtained by this method comprise a porous core (with pore sizes ranging from 10 to $100 \mu \mathrm{m}$ for SEVA-Cbased materials and from 100 to $1000 \mu \mathrm{m}$ for SCA) surrounded by a non-porous compact surface layer.

The porosity and pore morphology are obviously dependent on the amount of solid blowing agent and nature of the synthetic component of the polymeric blend.

The typical morphology of a SCA $+10 \%$ BA moulded sample is presented in Fig. $2 a$ and b. Fig. $2 b$ shows that some interconnectivity could be obtained.

With the use of an HA reinforcement, the formation of pores in the structure becomes more difficult (see Fig. 3), as the presence of the HA strongly increases the viscosity of the polymer based melt, which makes the diffusion of the $\mathrm{CO}_{2}$ generated throughout the bulk of the polymeric matrix much harder.
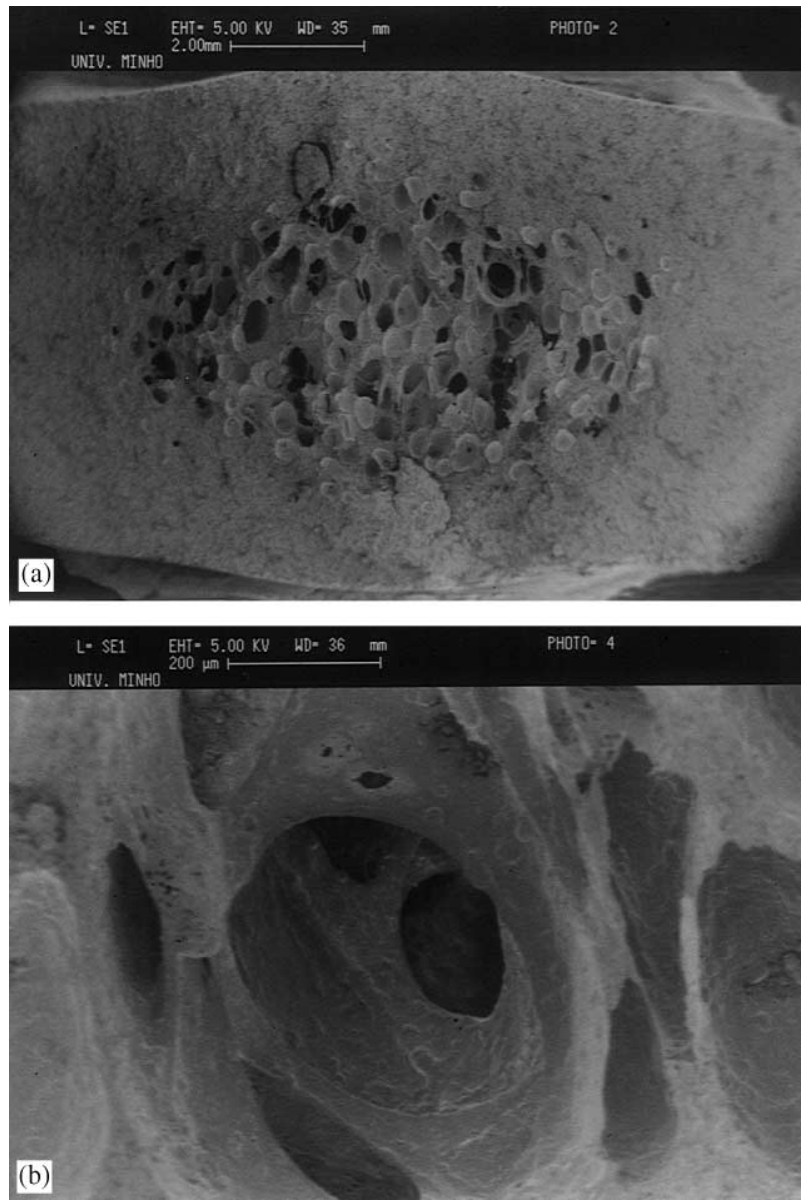

Fig. 2. (a) SEM micrograph displaying the typical morphology of a SCA $+10 \%$ BA moulded sample. (b) Magnification of (a) showing that some interconnectivity was obtained.

Nevertheless, the processing methodology and respective parameters should be optimised in order that these materials might be used for their aimed application. The processing of SEVA-C seemed to be harder to optimise than that of SCA. Further studies should be carried out to optimise the morphology developed during injection moulding. Some possibilities that are being assessed to improve the developed methodology are: (i) the use of different blowing agents and the incorporation of specific surfactants, (ii) bi-material injection moulding technologies and/or (iii) moulds that can move (slightly open) during the holding stage, allowing for the expansion of the bulk of the sample under controlled conditions.

\subsection{Mechanical properties}

In general, mechanical testing of the obtained materials showed that the method used in this study allows for the production of a material with a compact surface and a porous core without any significant decrease of the mechanical properties. 
Table 1

Quasi-static mechanical properties of SCA-based scaffolds

\begin{tabular}{lllll}
\hline Material & $\begin{array}{l}\text { Tensile modulus } \\
\left(E_{1 \%}, \mathrm{GPa}\right)\end{array}$ & $\begin{array}{l}\text { Ultimate tensile } \\
\text { strength }(\mathrm{UTS}, \mathrm{MPa})\end{array}$ & $\begin{array}{l}\text { Flexural modulus }\left(E_{\mathrm{f}}, \mathrm{GPa}\right) \\
\text { Notched/un-notched }\end{array}$ & $\begin{array}{l}\text { Flexural strength }\left(\sigma_{\mathrm{f}}, \mathrm{MPa}\right) \\
\text { Notched/un-notched }\end{array}$ \\
\hline SCA & $1.98 \pm 0.45$ & $30.06 \pm 0.83$ & $0.90 \pm 0.05 / 1.24 \pm 0.09$ & $16.57 \pm 1.45 / 54.77 \pm 1.46$ \\
SCA $+5 \%$ BA & $2.47 \pm 0.48$ & $27.25 \pm 2.16$ & $0.75 \pm 0.07 / 1.08 \pm 0.10$ & $13.92 \pm 1.43 / 47.39 \pm 1.52$ \\
SCA $+10 \%$ BA & $2.00 \pm 0.35$ & $27.74 \pm 1.60$ & $0.64 \pm 0.09 / 1.12 \pm 0.08$ & $15.07 \pm 1.34 / 43.10 \pm 1.34$ \\
\hline
\end{tabular}
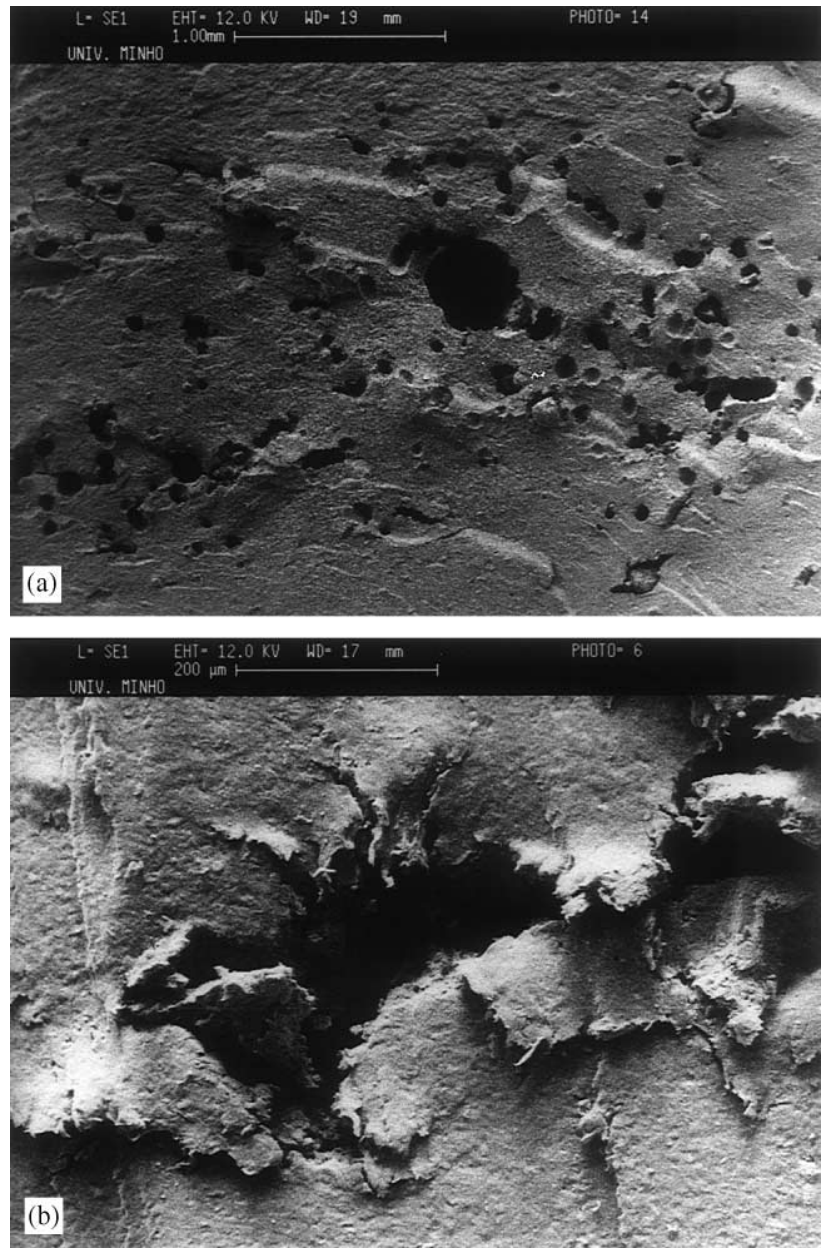

Fig. 3. (a) SEM micrograph displaying the typical morphology of a SEVA-C $+20 \%$ BA $+10 \%$ HA moulded sample. (b) Magnification of (a) showing in detail the shape of the pores obtained in this case.

From Tables 1 and 2 it can also be seen that the materials based on SCA have better tensile properties (namely the modulus) than the materials based on SEVA-C. This was not a surprise after observing the respective morphologies of the moulded samples. There is, for both blends, a decrease of the ultimate tensile strength (a maximum decrease of $21 \%$ for SEVA-C and around $9 \%$ for SCA) that is due to the presence of porosity in the bulk of the moulded parts that tends to act as stress concentrators. On the contrary, the stiffness
Table 2

Tensile properties of SEVA-C-based scaffolds

\begin{tabular}{lll}
\hline Material & $\begin{array}{l}\text { Tensile modulus } \\
\left(E_{1 \%}, \mathrm{GPa}\right)\end{array}$ & $\begin{array}{l}\text { Ultimate tensile } \\
\text { strength } \\
(\mathrm{UTS}, \mathrm{MPa})\end{array}$ \\
\hline SEVA-C & $1.62 \pm 0.09$ & $31.50 \pm 0.27$ \\
SEVA-C $+5 \%$ BA & $1.76 \pm 0.08$ & $31.50 \pm 1.13$ \\
SEVA-C $+10 \%$ BA & $1.74 \pm 0.12$ & $27.76 \pm 0.95$ \\
SEVA-C $+20 \%$ BA & $1.81 \pm 0.12$ & $25.03 \pm 0.83$ \\
\hline
\end{tabular}

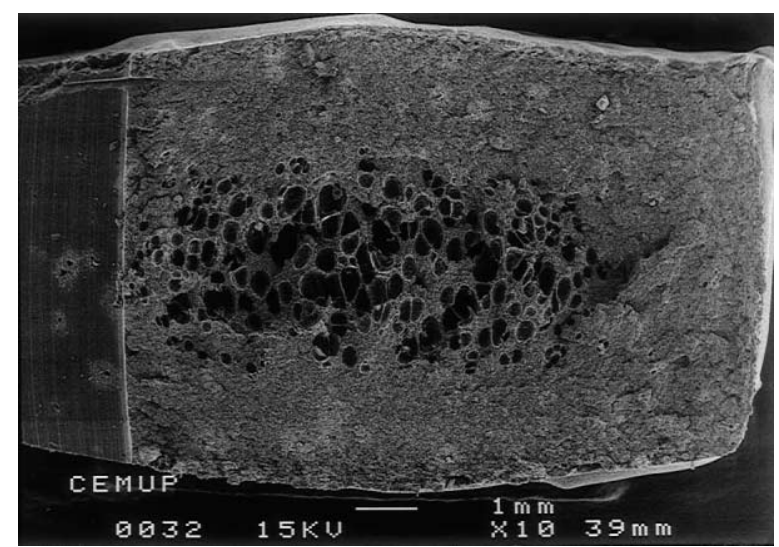

Fig. 4. SEM micrograph of a three-point-bending fracture surface of a notched sample obtained by injection moulding of SCA with $5 \%$ of blowing agent.

of the materials is slightly increased (a maximum increase of $12 \%$ for SEVA-C and around $25 \%$ for SCA) until a certain value of added blowing agent. This result is due to a very compact surface (packed both from the inside and from the mould side), resulting from the additional "holding pressure" generated by the blowing reaction. It is well know that the modulus is very surface-dependent [32] and consequently one might assume that this very compact outside layer is responsible for the slight enhancement/maintenance of the modulus. More interestingly, it seems that there is a blowing agent amount, $20 \%$ for SEVA-C and 5\% for SCA, that gives rise to the higher modulus and simultaneously to the worst UTS values.

The flexural modulus is not so surface dependent and, as may be also seen on Table 1 , the $E_{\mathrm{f}}$ tends to decrease slightly (around $9-13 \%$ ) for the foamed samples. Again 
Table 3

Impact properties of SEVA-C-based scaffolds

\begin{tabular}{llll}
\hline Material & $\begin{array}{l}\text { Peak force } \\
\left(F_{\mathrm{p}}, \mathrm{N}\right)\end{array}$ & $\begin{array}{l}\text { Impact strength Peak energy } \\
\left(\sigma_{\mathrm{s}}, \mathrm{MPa}\right)\end{array}$ & $\left(U_{\mathrm{p}}, \mathrm{J}\right)$ \\
\hline SEVA-C & $688.52 \pm 89.57$ & $47.81 \pm 6.21$ & $0.58 \pm 0.14$ \\
SEVA-C + 5\% BA & $493.36 \pm 76.50$ & $34.26 \pm 5.30$ & $0.28 \pm 0.05$ \\
SEVA-C + 10\% BA & $394.29 \pm 44.88$ & $27.38 \pm 2.00$ & $0.23 \pm 0.04$ \\
\hline
\end{tabular}

there is a decrease on the strength, with the $\sigma_{\mathrm{f}}$ values 21-26\% lower than the non-porous polymer (SCA). Fig. 4 shows the typical flexure fracture surface of a notched sample of SCA with $10 \%$ BA. From Fig. 4 it is clear that there was some pore coalescence generated by the mechanical solicitation. Also, it might be speculated that the pores tend to propagate in the direction of the notch side (on the left-hand side of Fig. 4).

Table 3 reports the results obtained in instrumented impact tests, in this case carried out only for SEVA-Cbased materials. The criteria for choosing SEVA-C for these tests was based on its ductility as compared to SCA that was found in previous studies [33]. It is well established that the impact properties are not so dependent on the surface of the moulded parts and are much more sensitive to the presence of pores on the samples. It should also not be forgotten that all samples have been notched. A clear decrease of all parameters, including the peak force, the impact strength (up to $42 \%$ ), and the peak energy (up to $60 \%$ ) with increasing porosity was observed. The analysis of the fracture surfaces by SEM (see Fig. 5), shows the coalescence of some micropores present in the structure, due to the high-speed loading. This is much more pronounced than what was observed on the quasi-static flexural tests.

\subsection{Degradation behaviour}

From Figs. 6 and 7 it is possible to say that for both materials the dry weight loss determined after different ageing periods increases significantly with increasing amounts of blowing agent. These results indicate that the higher porosity leads to a greater water uptake that is responsible for the faster degradation of the materials. The water uptake can reach values of around $30 \%$. In the more porous structures, EDS analysis showed the presence of some sodium and chloride in the bulk of the materials. Furthermore, it was observed that the compact outer layer tends to start degrading faster and becomes micro-porous after short immersion times. This is an indication that, eventually, the nutrients might be able to reach cells seeded on the porous part of the scaffolds due to their degradation and permeability to diffusion. Nevertheless only the study of cell seeding, attachment
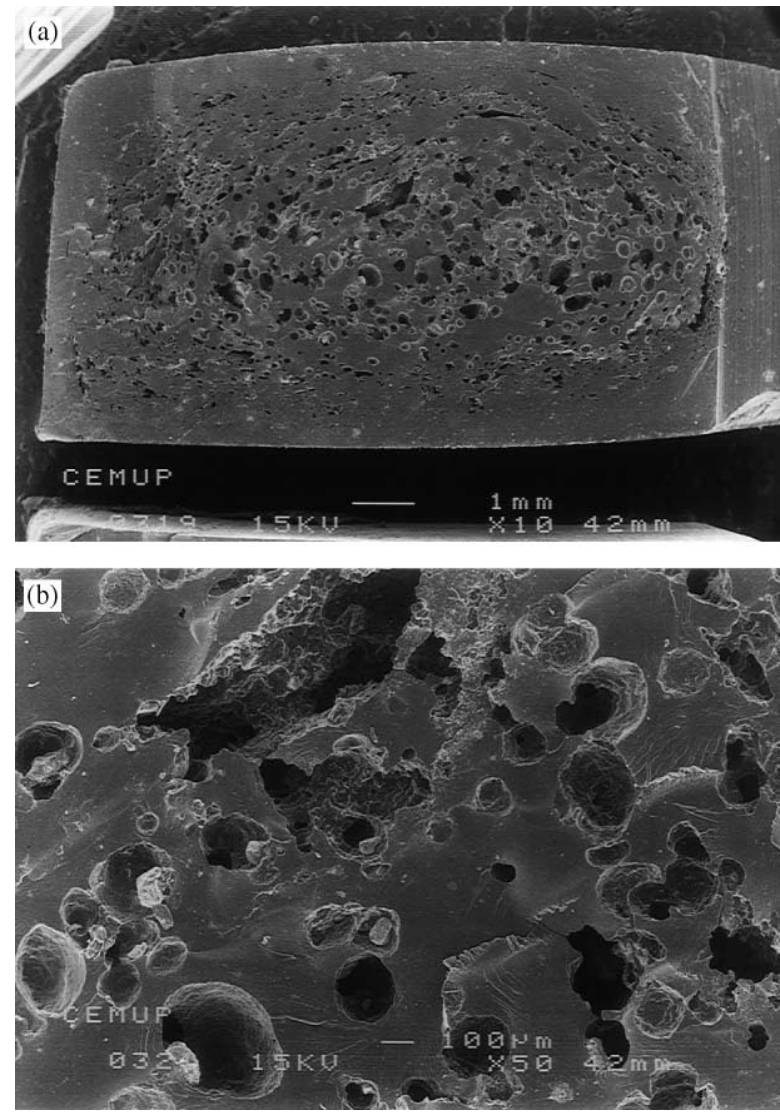

Fig. 5. (a) SEM micrograph of a impact fracture surface of a sample obtained by injection moulding of SEVA-C with $5 \%$ of blowing agent. (b) Magnification of (a) showing the interior porous structure in detail.

and proliferation on the proposed scaffolds and the posterior implantation of these tissue-engineered constructs will beyond any doubt prove the viability of the application of such type of materials.

Materials based on SCA underwent higher weight losses than the materials based on SEVA-C, probably due to the nature of the different synthetic component of the two starch-based blends and to the distinct morphology of these blends.

The mechanical properties, namely the modulus, do not exhibit significant changes during the studied degradation period (60 days), as shown in Fig. 8. This fact is very important because it indicates that these scaffolds will be able to maintain the necessary strength required in the initial period of the implantation of hard-tissue replacements, and then degrade chemically with chain breakage and leaching of molecular chains to the solution, as reported before [31] for non-porous injection moulded starch-based polymers.

The described process of obtaining these porous structures, does not influences the non-citotoxicity of the starch-based polymers, as reported in previous studies [34]. 

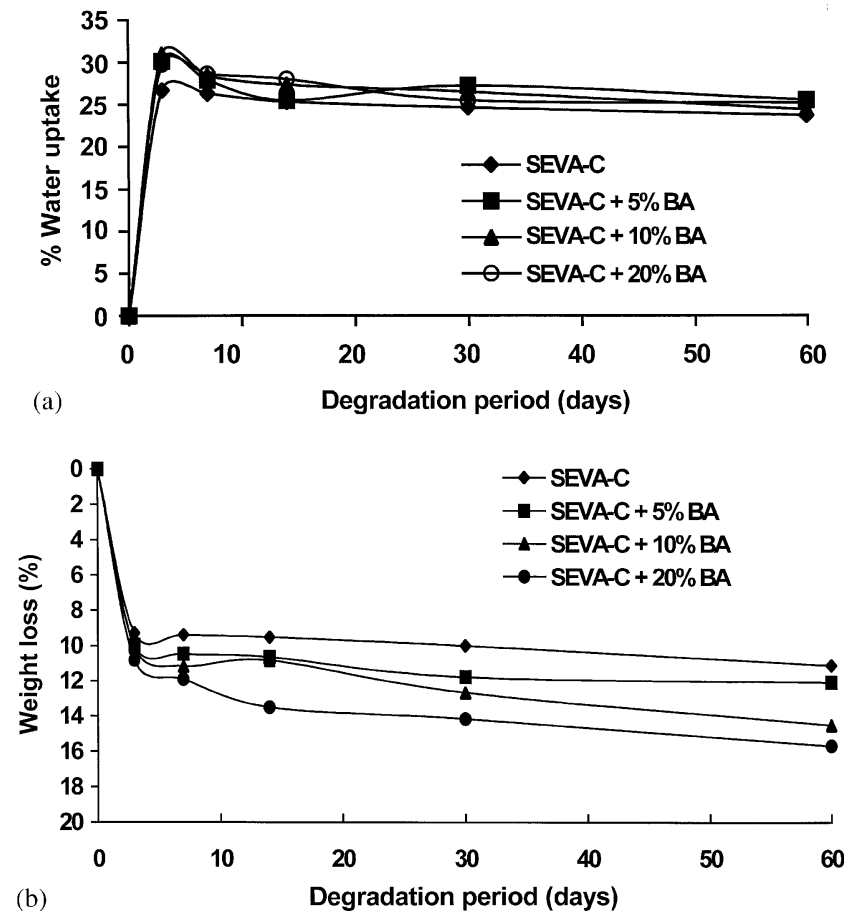

Fig. 6. (a) Water uptake versus degradation period for SEVA-C and SEVA-C-based scaffolds. (b) Dry weight loss versus degradation period for SEVA-C and SEVA-C-based scaffolds.
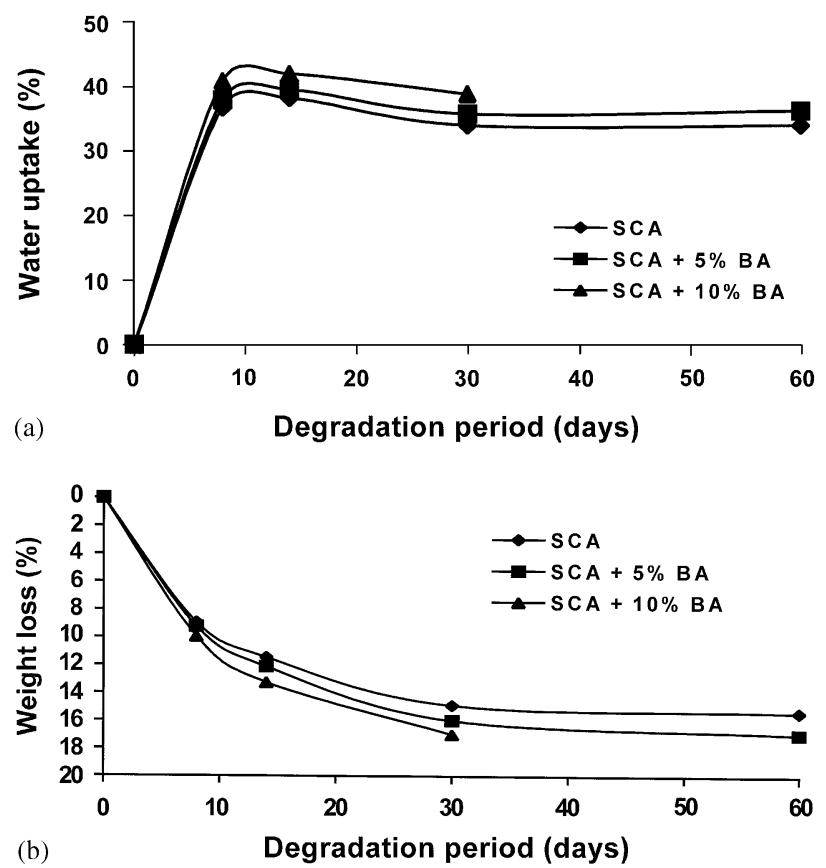

Fig. 7. (a) Water uptake versus degradation period for SCA and SCAbased scaffolds. (b) Dry weight loss versus degradation period for SCA and SCA-based scaffolds.

\section{Conclusions}

It was proved that it is possible to manufacture 3D scaffolds by melt-processing-based technologies that ex-

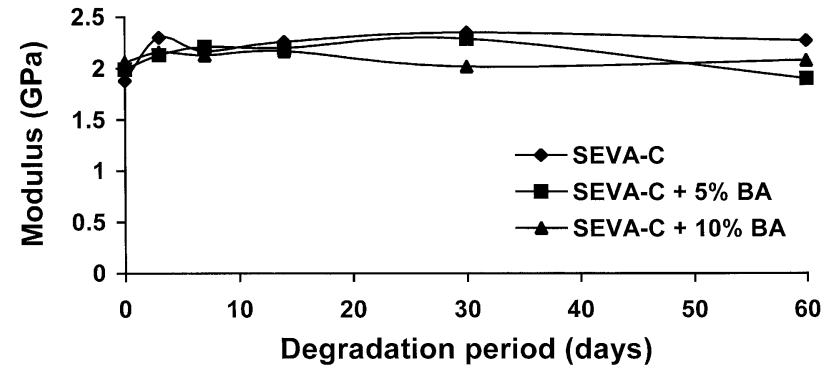

Fig. 8. Changes in the modulus versus degradation period.

hibit a compact surface and a porous core. These porous structures reveal a good compromise of mechanical and degradation properties. The manufacturing route allowed for the processing of materials with a porous core that disclose a mechanical performance similar to that of fully dense materials on both quasi-static tensile and flexural tests. Furthermore, the proposed methodology makes easy to produce complex shapes by a fast, reproducible, and automated technique such as injection moulding.

It may be possible to tailor the final properties and morphology of the materials by simply varying the processing parameters, materials formulation and quantity of blowing agent. The porosity, pore size and pore structure can be controlled by varying the amount of blowing agent without decreasing significantly the mechanical properties of both types of starch blends studied.

Materials manufactured from different starch-based blends, exhibit significant differences in their mechanical and degradation behaviour, which might make them suitable for different particular applications.

For obtaining scaffolds with enhanced mechanical properties associated to a bioactive behaviour, i.e., by using the HA reinforcement, it is necessary to optimise the processing conditions in order to allow for the production of higher porosity composite scaffolds.

The improvement of the practical way of implementing the proposed production concept might in the future allow for the tailoring of the mechanical properties, porosity and degradation behaviour of SEVA-C and SCA scaffolds. In fact, it could be possible to design scaffolds that might be adequate to a range of applications in the field of tissue engineering, but in particular to be used as high-strength scaffolds for hard-tissue regeneration.

\section{References}

[1] Freed LE, Vunjak-Novakovic. Culture of organized cell communities. Adv Drug Deliv Rev 1998;33:15-30.

[2] Thomson RC, Wake MC, Yaszemski M, Mikos AG. Biodegradable polymer scaffolds to regenerate organs. Adv Polym Sci 1995; 122:247-74. 
[3] Langer R. Selected advances in drug delivery and tissue engineering. J Controlled Release 1999;62:7-11.

[4] Lu L, Mikos A. The importance of new processing techniques in tissue engineering. MRS Bull 1996;21:28-32.

[5] Langer R, Vacanti JP. Tissue engineering. Science 1993; 260:920-5.

[6] Zhang R, Ma PX. Poly( $\alpha$-hydroxyl acids)/hydroxyapatite porous composites for bone-tissue engineering. i. Preparation and morphology. J Biomed Mater Res 1999;44:446-55.

[7] Minuth WW, Sittinger M, Kloth S. Tissue engineering generation of differentiated artifitial tissues for biomedical applications. Cell Tissue Res 1998;291:1.

[8] Piskin E. Biomaterials in different forms tissue engineering - an overview. Mater Sci Forum 1997;250.

[9] Agrawal CM, Athanasiou KA, Heckman JD. Biodegradable PLA-PGA polymers for tissue engineering in orthopaedics. Mater Sci Forum 1997;250:115-228.

[10] Rotter N, Aigner J, Nauman A, Planck H, Hammer C, Burmester G, Sittinger M. Cartilage reconstruction in head and neck surgery: comparasion of resorbable polymer scaffolds for tissue engineering of human septal cartilage. J Biomed Mater Res 1998;42:347-56.

[11] Shapiro L, Cohen S. Novel alginate sponges for cell culture and transplantation. Biomaterials 1997;18:583-90.

[12] Simske SJ, Ayers RA, Bateman TA. Porous materials for bone engineering. Mater Sci Forum 1997;250:151-82.

[13] Maquet V, Jerome R. Design of macroporous biodegradable polymer scaffolds for cell transplantation. Mater Sci Forum 1997;250:15-42.

[14] Whang K, Healy KE, Elenz DR, et al. Engineering bone regeneration with bioabsorbable scaffolds with novel microarchitecture. Tissue Engng 1999;5:35-51.

[15] Saad B, Ciardelli G, Matter S, et al. Degradable and highly porous polyesterurethane foam as biomaterial: effects and phagocytosis of defradation products in osteoblasts. J Biomed Mater Res 1998;39:594-602.

[16] Thomson R, Yaszemski M, Mikos A. Polymer scaffold processing. In: Lanza R, Langer R, Chick W, editors. Principles of tissue engineering. New York: Academic Press, 1997. p. 263-72.

[17] Mikos AG, Thorsen AJ, Czerwonka LA, Bao Y, Langer RB. Preparation and characterization of poly(L-lactid acid) foams. Polymer 1994; 1068-1077.

[18] Mikos AG, Sarakinos G, Leite SM, Vacanti JP, Langer R. Laminated three-dimensional biodegradable foams for use in tissue engineering. Biomaterials 1993;14:323-30.

[19] Mikos AG, Bao Y, Cima LG, Ingeber DE, Vacanti JP, Langer RB. Preparation of poly(glycolic acid) bonded fiber structures for cell attachment and transplantation. J Biomed Mater Res 1993;27:183-9.

[20] Hinrichs W. Porous polymer structures for tissue regeneration. PhD Thesis, Univ Twente, The Netherlands, 1992.
[21] Mooney DJ, Baldwin DF, Suh NP, Vacanti JP. Novel approach to fabricate porous sponges of poly(D,L-lactid-co-glycolic acid) without the use of organic solvents. Biomaterials 1996; 17:1417-22.

[22] Gomes M.E, Ribeiro A, Malafaya PB, Reis RL, Cunha AM. A new approach based on injection moulding to produce biodegradable starch based scaffolds. 25th Annual Meeting of the Society for Biomaterials, Providence, USA, 1999. p. 224.

[23] Thompson RC, Yaszemski MJ, Powders JM. Fabrication of biodegradable polymer scaffolds to engineer trabecular bone. J Biomater Sci-Polym Edn 1995;7:23-8.

[24] Ribeiro A, Malafaya PB, Reis RL. Microwave based methodologies for the production of polymeric and ceramic porous arquitechtures to be used in bone replacement, tissue engineering and drug delivery. 25th Annual Meeting of the Society for Biomaterials, Providence, USA, 1999. p. 555.

[25] Jiang G, Shi D. Coating of hydroxylapatite on highly porous $\mathrm{Al}_{2} \mathrm{O}_{3}$ substrate for bone substitutes. $\mathrm{J}$ Biomed Mater Res 1997;43:77-88.

[26] Oliveira AL, Elvira C, Vázquez B, San Roman J, Reis RL. Surface modifications tailors the characteristics of biomimetic coatings nucleated on starch based polymers. J Mater Sci: Mater Med 1999;10:827-35.

[27] Vaz CM, Cunha AM, Reis RL. Degradation model of starchEVOH/HA composites. Macromolecular Symposia 2001, in press.

[28] Mano JF, Vaz CM, Mendes SC, Reis RL, Cunha AM. Dynamic mechanical properties of hydroxylapatite reinforcement and porous starch based degraded biomaterials. J Mater Sci: Mater Med 1999;10:857-62.

[29] Pereira CS, Cunha AM, Reis RL, Vázquez B, San Roman J. New starch-based thermoplastic hydrogels for use as bone cements or drug-delivery carriers. J Mater Sci: Mater Med 1998;9:825-33.

[30] Reis RL, Cunha AM, Fernandes MH, Correia RN. Treatments to induce the nucleation and growth of apatite-like layers on polymeric surfaces and foams. J Mater Sci: Mater Med 1997;8:897-905.

[31] Reis RL, Mendes SC, Cunha AM, Bevis MJ. Processing and in-vitro degradation of starch/EVOH thermoplastic blends. Polym Int 1997;43:347-53.

[32] Brewer GW. Properties of thermoplastic structural foams. In: Engineered materials handbook, vol. 2. Cleveland, OH: ASM International, 1989. p. 508-13.

[33] Reis RL, Cunha AM, Bevis MJ. Using non-conventional processing routes to develop anisotropic and biodegradable composites of starch based thermoplastics reinforced with bone-like ceramics. J Appl Med Pol 1998;2:49-53.

[34] Mendes S, Bovell Y, Reis R, van Blitterswijk C, de Bruijn J. Biocompatibility testing of novel starch based polymers and composites with potential application in orthopaedic surgery. 24th Annual Meeting Society for Biomaterials, San Diego, USA, 1998. p. 9. 